\title{
EXPECTATIONS AND THE REAL BALANCE EFFECT*
}

\author{
by \\ Jean-Michel GRANDMONT \\ September 1980
}

$\mathrm{N}^{\circ} 8020$

* This is a preliminary draft of the first chapter of a forthcoming monograph on Neoclassical Monetary Theory. Partial support from the University of Bonn and from the National Science Foundation under grant \# SOC 78-06157 to the Center for Analytic Research in Economics and the Social Sciences at the University of Pennsylvania is gratefully acknowledged. 


\section{EXPECTATIONS AND THE REAL BALANCE EFFECT}

The subject of this lecture is mainly to examine with the help of a simple microeconomic model, two propositions which play a significant role in neoclassical monetary theory.

The first proposition is that "money does not matter". Or more precisely, if the mere presence of money as a medium of exchange and as an asset is important for the smooth functioning of the economy, the quantity of money is innessential. This is the quantity Theary tradition, which claims that a change in the money stock will change in the same proportion all nominal values, but will have no effect on "real" variables. This old tradition still plays an important role in modern thinking. The first purpose of this chapter is to clarify the exact meaning of this theory and its domain of validity.

The second issue will be the belief, which is commonly shared by neoclassical economists but is opposed by a few Keynesian theorists, that a short run Walrasian equilibrium where money has positive exchange value usually exists. We shall investigate this question in this lecture by looking at a simple model involving only outside money. Money is then printed money, and can be regarded as a part of private net wealth. In such a context, the neoclassical argument relies essentially upon the' existence of a "real balance effect". When money prices of goods are low, the "purchasing power" of the agents' initial money balances is large. This fact should generate according to this viewpoint an excess demand on the goods markets at sufficientiy low levels of prices. Conversely, the "purchasing power" of the agents' initial cash balances becomes small 
when money prices are large, so that an excess supply of goods should eventually appear. Thus by continuity, an equilibrium should exist in between.

It will be shown that this argument is wrong because it neglects the intertemporal character of the choices made by the agents. Modeling explicitly these choices will lead us to the conclusion that the real balance effect is typically too weak to guarantee the existence of a short run equilibrium where money has positive value. As a matter of fact, the existence of such an equilibrium position essentially requires, as we shall see, that the price forecasts of some agent be substantlally insensitive to current prices. The relative variations of current and expected prices then generate an "intertemporal substitution effect" between current and future goods which reinforces the real balance effect, and is strong enough to equilibrate the market.

Such conditions on expectations are quite unlikely to prevail in reality. Indeed, the agents' price expectations are presumably very sensitive to the price levels which they observe, especially in periods of significant inflation or deflation. In particular, expected prices are likely to be biased upwards in the case of inflatien, and downwards in the case of deflation. It will be shown that in such circumstances, a short run equilibrium typically does not exist. The conclusion which will emerge therefore from our analysis is that the existence of a short run Walrasian equilibrium where money has positive value is somewhat problematic in actual market economies, contrary to what most neoclassical economists used to believe. 
In order to focus the attention on the essentials, the analysis will be conducted within the framework of a simple model. Paper money will act as the numeraire and only store of value. Its stock, which can be viewed as the sum of the government's past deficits, will be assumed to be constant over time (outside money). Dutput, or equivalently, the stream of the agents' real income will be taken as exogenous. This hypothesis is in fact immaterial ; analogous results would be obtained with variable output. The main question will be to see whether there exists an equilibrium either in the short run or in the long run, where the agents are willing to hold the outstanding quantity of money, and to investigate the properties of these equilibria (if any) in relation with the money stock. No attention will be paid to the services that actual money yields in aur economies (medium of exchange, liquidity). The reason is that taking into account these otherwise quite important functions of money would change neither the need for raising the questions that we shall consider nor the conclusions that we shall reach. Indeed, modern money can serve as a medium of exchange and/or as an asset if and only if it has a positive exchange value in equilibrium. 


\section{CLASSICAL AND NEOCLASSICAL VIEWS ON MONEY.}

We first proceed to a brief overview of the issues which we shall be concerned with. In order to fix the ideas, let us assume that there are $\ell$ perishable goods, indexed by $h=1, \ldots, \ell$, traded in each peried at money prices $P=\left(p_{1}, \ldots, p_{\ell}\right)$, whose equilibrium values are to be determined by the market. Fiat money, on the other hand, is the sole asset, and its stock is constant over time.

Classical economists (e.g. Fisher) took the view that in order to find the level of equilibrium prices, one could reason in two steps. Markets for Ecods (the "real sector") would determine equilibrium relative prices, i.e., the ratios $\mathrm{p}_{\mathrm{h}} / \mathrm{p}_{k}$, and quantities of goods exchanged in equilibrium. Then consideration of the money market would determine the level of equilibrium money prices, which would be in fact proportional to the money stock. The view that the real and money markets can be considered separately in this way is called the Classical Dichotomy. The proportionality of the money prices to the money stock is the essence of the quantity Theory.

To be more precise, let us consider a specific agent a. His array of excess demands for goods is written as a function of money prices alone, $\dot{z}_{a}(p)=\left(z_{a 1}(p), \ldots, z_{a l}(p)\right)$. Equilibrium of the goods markets would require that aggregate excess demand is zero :

(A)

$$
\sum_{a} z_{a}(p)=0
$$


where the summation sign runs over the set of all agents a. Classical economists would assume that $(A)$ displays the usual properties of an ordinary Walrasian system, that is, homogeneity of degree zero of excess demand functions, i.e., $z_{a}(\lambda p)=z_{a}(p)$ for every $p$ and every positive $\lambda$, and what has been called Say's Law by Lange and Patinkin : The value of aggregate excess demand $p \cdot \sum_{a} z_{a}(p)$ is zero for every price system $p$. The structure of equations (A) was understood to depend significantly on the mere presence of money in the economy. The main point is that these equations were assumed to be independent of the quantity of money, and of its distribution among traders.

One must consider next the money market. Let $m_{a}^{d}(p)$ be agent a's demand for (nominal) money when the price system is $p$. The classical view that only "real" money balances matter can be expressed here be the assumption that $m_{a}^{d}(p)$ is homogenous of degree 1 in $p$, i.e., $m_{a}^{d}(\lambda p)=\lambda m_{a}^{d}(p)$ for every $p$ and $\lambda$. Then equilibrium of the money market requires that aggregate demand for money be equal to the amount of money $M$ in circulation :

(B)

$$
\sum_{a} m_{a}^{d}(p)=M
$$


Writing down a system of equations like $(A)$ and $(B)$ seems to formulate in a corisistent way Classical views about the Classical Dichotomy and the quantity Theary. Modern competitive equilibrium theory tells us that (A) has indeed solution(s) in $p$ under rather general conditions. Due to the homogeneity of degree zero of $(A)$, such solutions are defined only up to a positive real number. Consideration of the real sector alone leads to the determination of equilibrium relative prices and real quantities exchanged. On the other hand, for any solution $\bar{p}$ of $(A)$, there exists a unique $\lambda$ such that $\sum_{a} m_{a}^{d}(\lambda \bar{p})=M$, provided that aggregate demand for money at prices $\bar{p}$, i.e. $\sum_{a} m_{a}^{d}(\bar{p})$, is positive. Money prices are determined by the money market. Lastly, the homogeneity properties of the system imply that, say, a doubling of the quantity of money $M$ leads to a doubling of money prices and of nominal money balances, leaving unchanged relative prices and real quantities exchanged. Whether the system $(A)$ and $(B)$ is intended to represent the behavior of an economy with outside money in the short run or in the long run (i.e., along stationary states) has been the object of some debate. In particular, Patinkin argued that $(A)$ and $(B)$ cannot apply to the short period, since this system neglected the influence of a change of the level of money prices on the agents' behavior in the goods markets via the real balance effect, i.e., the effect of a change of money prices on the "purchasing power" of the agents' initial money holdings $\bar{m}_{a}$. A related criticism made by Patinkin is that agents face a budget constraint. If the system $(A)^{\prime}$ and $(B)$ applies to the short period, it should satisfy therefore Walras Law :

$$
\sum_{a} p \cdot z_{a}(p)+\sum_{a} m_{a}^{d}(p)=\sum_{a} \bar{m}_{a}=M
$$


for every $p$. But adding this identity to the system leads to major drawbacks. Together with Say's Law, this.identity implies $\sum_{a} m_{a}^{d}(p)=M$ for every $P$, in which case any solution of $(A)$ fulfills $(B)$ : the level of money prices becomes indeterminate. Even if one puts aside Say's Law, Walras Law contradicts the assumed homogeneity properties of the functions $z_{a}(p)$ and $m_{a}^{d}(p)$. For these imply that the left hand side of the foregoing identity is homogenous of degree 1 in prices, while the right hand side is a constant number independent of them.

These arguments led Patinkin to the conclusion that in order to get a consistent monetary theory applicable to short period problems, the excess demands for goods and for money balances should be made dependent upon initial money holdings $\bar{m}_{a}$, and that a short period equilibrium should be described as the outcome of the following system of equations :

(C)

$$
\sum_{a} z_{a}\left(p, \bar{m}_{a}\right)=0
$$

(D)

$$
\sum_{a} m_{a}^{d}\left(p, \bar{m}_{a}\right)=\sum_{a} \bar{m}_{a}
$$

He assumed that the system obeyed Walras Law, that is

$$
p \cdot \sum_{a} z_{a}\left(p, \bar{m}_{a}\right)+\sum_{a} m_{a}^{d}\left(p, \bar{m}_{a}\right)=\sum_{a} \bar{m}_{a}
$$


for every $p$, as a consequence of the agents' budget constraints. On the other hand, he did not assume that the functions $z_{a}\left(p, \bar{m}_{a}\right)$ and $m_{a}^{d}\left(p, \bar{m}_{a}\right)$ had the homogeneity properties postulated in the Classical system $(A)$ and $(B)$, insisting on the presence of a real balance effect. Instead, he observed that only "real" money balances matter, and assumed accordingly that the excess demand functions $z_{a}\left(p, \bar{m}_{a}\right)$ were homogenous of degree 0 and the money demand functions $m_{a}^{d}\left(p, \bar{m}_{a}\right)$ were homogenous of degree 1 in $\left(p, \bar{m}_{a}\right)$.

Modern restatements of monetary theory as exemplified by the works of Friedman and his followers would yield the same kind of equations when applied to the present context. This line of theorizing emphasizes rightily that money should be treated as a particular capital good. According to this viewpoint, the agents' short period demand functions should depend in the present context on initial wealth (here initial money holdings $\bar{m}_{a}$ ), on current and expected real incomes (taken here as exogenous), on current prices and the "expected rate of inflation". As the expected rate of inflation is mostly taken as exogenous in the short run by writers of this school, one falls back to the same equations $(C)$ and $(D)$, displaying the same properties.

Examination of equations (C) and (D) leads to two immediate conclusions. 
First, the Classical Dichotomy is invalid in the short period. For Walras Law implies that any solution $p$ of $(C)$ satisfies $(D)$. Consideration of the real sector alone determines not only relative prices and real variables, but also the level of money prices and all nominal values, in contradiction to what the classics claimed.

Second, the Quantity Theary must be reformulated in order to be valid in the short run. It is clear that a change of the money stock which alters the distribution of initial money holdings $\bar{m}_{a}$ among agents has distributional effects and thus is likely to modify relative prices. On the other hand, an equiproportionate change in initial money balances (every $\bar{m}_{a}$ being changed to $\lambda \bar{m}_{a}$ ) will change in the same proportion the level of money prices and nominal money balances at the end of the period, but will leave unaltered relative prices and real variables, whenever the functions $z_{a}\left(p, \bar{m}_{a}\right)$ and $m_{a}^{d}\left(p, \bar{m}_{a}\right)$ are assumed to be homogenous of degree 0 and 1 , respectively, with respect to $\left(p, \bar{m}_{a}\right)$. Indeed, under these homogeneity assumptions, if $p$ is a solution of $(C)$ and $(D)$ when initial money holdings are $\bar{m}_{a}$, $\lambda p$ must be a solution of the same equations when every initial money stock $\bar{m}_{a}$ is multiplied by $\lambda$.

While Patinkin's attempt to integrate money in Value Theory was recognized as a remarkable achievement, it has generated important and as yet unsettled controversies. In particular, the empirical relevance of the real balance effect, which is essential for Patinkin's theory (and indeed most of neoclassical monetary theory) has been seriously questioned. Many economists believe nowadays that this effect plays little role in the short run. This point is related to 
a problem which has received little attention : does a system like (C) and (D) have a solution under reasonnable circumstances ? The question is a great practical interest, for it conditions the applicability of such a system, which is common to many neoclassical monetary models, to short run monetary phenomena. Since the usual (heuristic) arguments asserting the existence of such a solution rely heavily upon the presence of a real balance effect and upon its strength, the matter is a serious one which deserves careful examination.

It has also been argued that, while Patinkin's critique of the Classical views was apparently valid for the short period, the Classical Dichotomy and the Quantity Theory retained their full force when applied to long run (i.e. stationary) monetary phenomena (Archibald and Lipsey, Samuelson). According to this view, the system of equations (A) and $(B)$ is not intended to represent the result of an adjustment of prices within a given period nor over time. Rather, the functions $z_{a}(p)$ and $m_{a}^{d}(p)$ appearing in these equations should be interpreted as describing the stationary net trades and money stocks detained by the agents along stationary states, when prices remain constant.

This brief review shows that, although a great deal of work has been done, a fully consistent integration of money and Value Theory in a neoclassical framework is still needed. The primary task of this chapter is to look at this matter. 


\section{STRUCTURE OF THE MODEL.}

Consider a simple exchange economy, where time is divided into infinitely many discrete periods. There are $\ell$ consumption goods available in each period. The simplifying assumption that the agents' real income is fixed is expressed by the fact that each agent owns in each period an exogenously given endowment of consumption goods. The endowments cannot be stored, and must be traded and consumed within the period at which they are available. On the other hand, paper money is the only store of value, and its stock is constant over time. Thus, at any date, the treders (consumers) come to the market with their endowment of goois, and their cash balances carried over from the past. The short run competitive equilibrium of the markets at that date will determine Walrasian money prices of the goods $p=\left(p_{1}, \ldots, p_{\ell}\right)$, the consumers' net trades in the good markets and the money balances that they will hold until the next period.

The framework in which we choose to work is that of an overlapping generation model, without bequest (Samuelson). There are accordingly various "types" of consumers. Each type is described by : the number of periods during which agents of this type live, the endowments of consumption goods that these agents own in each period of their life, and their preferences among consumption streams during their lifetime. An important feature of the model is the fact that there are always "newborn" agents coming into the market at any date. Thus when an agent wishes to get rid of his cash balances at some time in his life, there will be always younger agents living in the same period for whom money may have value for saving purposes. 
We consider first this economy in a given period, which we call period 1, and study its properties in the short period (sections 3-5). At this stage, there is no need to be specific about the characteristics of each "type" of agent nor about the demographic structure of the model. We shall make such a specification in section 6 , when studying stationary states of this economy. For the moment, what we need is to know the characteristics of every agent a living in the period under examination, i.e.,

(i) the number $n_{a}$ of remaining periods for which he is going to live including the current one.

(ii) his preferences which are represented by a utility function $u_{a}$ which depends upon current and future consumption $c_{t}$, $t=1, \ldots, n_{a}$, where $c_{t}$ is a vector with $l$ nonnegative components.

(iii) his endowment of consumption goods, eat, in every remaining period of his life, $t=1, \ldots, n_{a}$, where again, $e_{\text {at }}$ is a vector with $\ell$ components.

(iv) the money stock $\bar{m}_{a}$ he owns at the outset of period 1 , which is the result of his past saving and consumption decisions.

We shall make from now on the following traditional assumptions. 
(a) The utility function $u_{a}$ is continuous, increasing, and strictly quasi-concave for every a.

(b) All components of the endoument vector, $e_{a t}$, are positive for every a and $t$.

(c) The total money stock $M=\sum_{a} \bar{m}_{a}$ is positive. 


\section{SHORT RUN DEMAND FUNCTIONS.}

Consider a typical agent at date 1, the "current period". His prablem (dropping the subscript a for convenience) is to choose his current consumption of goods $\sigma_{1} \geqq 0$, his current money holdings $m_{1} \geqq 0$, and to plan his futurs consumptions $\left(c_{2}, \ldots, c_{n}\right) \geqq 0$ and money holdings $\left(m_{2}, \ldots, m_{n}\right) \geqq 0$. If current money prices of goods are represented by the vector $p_{1}$, and if the agent expects the prices $p_{2}, \ldots, p_{n}$ to prevail in the future, this choice will be the solution of the following problem :

Maximize $u\left(c_{1}, \ldots, c_{n}\right)$ with respect to $\left(c_{1}, \ldots, c_{n}\right) \geqq 0$ and $\left(m_{1}, \ldots, m_{n}\right) \geqq 0$ subject to the current and expected budget constraints :

$$
\begin{aligned}
& p_{1} c_{1}+m_{1}=p_{1} e_{1}+\bar{m} \\
& p_{t} c_{t}+m_{t}=p_{t} e_{t}+m_{t-1}, \quad(t=2, \ldots, n) .
\end{aligned}
$$

This decision making problem has a solution, which is unique, when current and expected prices are positive. This solution gives rise to an excess demand for consumption goods $c_{1}-e_{1}$ and a demand for money $m_{1}$ which are actually expressed on the market (plans for the future remain in the mind of "the trader). These demands depend upon initial cash holdings $\bar{m}$, on current prices $p_{1}$, on the sequence of expected prices $p_{t}$, and on current and future real incomes $e_{1}, \ldots, e_{n} \cdot$ 
The solution of (I) displays very simple and straightforward homogeneity properties with respect to the initial money stock and the sequence of current and expected prices. Consider a change of $\bar{m}$ in $\lambda \bar{m}$, of $p_{1}$ and $p_{t}$ in $\lambda p_{1}$ and $\lambda p_{t}(t=2, \ldots, n)$ and call (I') this new problem. No "real" change has been made in the constraints faced by the agent. In fact, it is immediate to verify that $\left(c_{1}, \ldots, c_{n}\right)$ and $\left(m_{1}, \ldots, m_{n}\right)$ are solutions of (I) if and only if $\left(c_{1}, \ldots, c_{n}\right)$ and $\left(\lambda m_{1}, \ldots, \lambda m_{n}\right)$ are solutions of $\left(I^{\prime}\right)$, a property which we can call Absence of Money Illusion. We have obtained in particular

(1) (Absence of Money Illusion). The excess demand for goods $c_{1}-e_{1}$ arising from $(I)$ is homogenous of degree 0 in the initial money stock $\bar{m}$, current prices $p_{1}$ and expected prices $p_{2}, \ldots, p_{n}$. The corresponding money demand $m_{1}$ is homogenous of degree 1 in the same variables.

In order to complete our specification of a trader's behavior in the short run, it is necessary to describe how prices expectations are formed. The agent's expectations are functions of his information on past history and on the current state of the economy. Since past history is fixed in a short period analysis and cannot be altered by current events, we shall not mention explicitly its influence at the formal level. On the other hand, we shall assume that the only information our agent has on the current state of the economy is described by the current price system $p_{1}$, and shall write expected prices $p_{t}$ as a function $\psi_{t}\left(p_{1}\right)(t=2, \ldots, n)$. Expected prices are thus independent of the agent's own actions. 
This formulation is warranted in a competitive framework where the number of traders is implicitly assumed to be large, since in that case, every agent can have only a negligible influence on market prices by varying his own decisions.

Let us call (II) the problem obtained from (I) by changing $p_{t}$ in $\psi_{t}\left(p_{1}\right)$ for $t=2, \ldots, n$ :

Maximize $u\left(c_{1}, \ldots, c_{n}\right)$ with respect to $\left(c_{1}, \ldots, c_{n}\right) \geqq 0$ and $\left(m_{1}, \ldots, m_{n}\right) \geqq 0$ subject to :

$$
\begin{aligned}
& p_{1} c_{1}+m_{1}=p_{1} e_{1}+\bar{m} \\
& \psi_{t}\left(p_{1}\right) c_{t}+m_{t}=\psi_{t}\left(p_{1}\right) e_{t}+m_{t-1}, \quad(t=2, \ldots, n) .
\end{aligned}
$$

The solution to this problem yields an excess demand for goods $c_{1}-e_{1}$ and a demand for money $m_{1}$ which are expressed by the agent on the market in response to $p_{1}$. They depend upon the initial money stock $\bar{m}$ and upon current prices $p_{1}$ (and implicitly, on the trader's information on past history as well as on current and future endowments of goods). We can write them $z_{a}\left(p_{1}, \bar{m}_{a}\right)$ and $m_{a}^{d}\left(p_{1}, \bar{m}_{a}\right)$ respectively, reintroducing finally the agent's subscript $a$.

This formulation is similar to the one which we described in the preceding section. We are thus able to discuss on a precise basis various properties of short run demand functions.

First, every agent must fulfill its current budget constraint, $p z_{a}\left(p_{1}, \bar{m}_{a}\right)+m_{a}^{d}\left(p_{1}, \bar{m}_{a}\right)=\bar{m}_{a}$. Therefore aggregate excess demands satisfy Walras Law: 


$$
p_{1} \sum_{a} z_{a}\left(p_{1}, \bar{m}_{a}\right)+\sum_{a} m_{a}^{d}\left(p_{1}, \bar{m}_{a}\right)=\sum_{a} \bar{m}_{a} \text { for every positive } p_{1} \text {. }
$$

On the other hand, aggregate excess demand for goods does not in general satisfy Say's Law, $p_{1} \sum_{a} z_{a}\left(p_{1}, \bar{m}_{a}\right)=0$ for every $p_{1}$ since at some prices traders can find it profitable to save or dissave by adding to or subtracting from their initial cash balances $\bar{m}_{a}$.

Second, we must examine if the functions $z_{a}\left(p_{1}, \bar{m}_{a}\right)$ and $\mathrm{m}_{a}^{\mathrm{d}}\left(\mathrm{p}_{1}, \overline{\mathrm{m}}_{\mathrm{a}}\right)$ are homogenous of degree 0 and 1 respectively with respect to current prices $p_{1}$ and initial cash balances $\bar{m}_{a}$, as Patinkin and neoclassical monetarists often assume. In view of the Absence of Money Illusion property stated in (1), the answer is in general no, unless the agents' expected prices $\psi_{a t}\left(p_{1}\right)$ are unit elastic with respect to current prices, that is to say, $\psi_{a t}\left(\lambda p_{1}\right)=\lambda \psi_{a t}\left(p_{1}\right)$ for every $p_{1}$ and $\lambda$, and for every $t$. This is in particular the case if one assumes that expected prices are always equal to current ones, as Patinkin did, (static expectations), or that every agent's expected rate of inflation $\pi_{a}^{e}$ depends only in the short run on past history but not on current prices $\left(\psi_{a t}\left(p_{1}\right)=\left(1+\pi_{a}^{e}\right)^{t-1} p_{1}\right.$ for every $\left.t\right)$, as neoclassical writers often do. Such assumptions appear therefore to be highly specific : strict proportionality of expected prices with respect to current ones is quite unlikely, since expectations depend on the sequence of past prices as well. To sum up,

The functions $z_{a}\left(p_{1}, \bar{m}_{a}\right)$ and $m_{a}^{d}\left(p_{1}, \bar{m}_{a}\right)$ are homogenous of degree 0 and degree 1 , respectively, with respect to $p_{1}$ and $\bar{m}_{a}$ if expected prices are unit elastic with respect to current prices $\left(\psi_{\text {at }}\left(\lambda p_{1}\right)=\lambda \psi_{\text {at }}\left(p_{1}\right)\right.$ for every $p_{1}$ and $\left.\lambda, t=2, \ldots, n_{a}\right)$. 
Finally, this formulation allows for the presence of a real balance effect. Indeed, a change in the level of current prices alters the purchasing power of initial cash balances $\bar{m}_{a}$, and thus has a potential influence upon the traders' behavior in the goods markets. As a matter of fact, this real balance effect appears in its pure form, when prices expectations are unit elastic with respect to current prices. In such a case, multiplying current prices $p_{1}$ by $\lambda$, and thus expected prices by the same factor, is equivalent to dividing initial cash balances $\bar{m}_{a}$ by $\lambda$. Indeed, (2) implies that $z_{a}\left(p_{1}, \bar{m}_{a}\right)$ is then homogenous of degree 0 with respect to $p_{1}$ and $\bar{m}_{a}$, in which case

$$
z_{a}\left(\lambda p_{1}, \bar{m}_{a}\right)=z_{a}\left(p_{1}, \frac{\bar{m}_{a}}{\lambda}\right)
$$

for every positive $\lambda$. The real balance effect is thus a pure "income" or "wealth" effect. A proportional increase of current prices is therefore likely to generate in the case of unit elastic expectations a reduction of the demand for current goods.

The foregoing argument explains in particular why Neoclassical writers considered the real balance effect as the main equilibrating mechanism in economies like the one which we consider, since they assumed, explicitly or implicitly, that price expectations were unit elastic.

The elasticity of price expectations with respect to current prices, however, differs typically from unity. In that case, an equiproportionate increase of current prices generates in addition to the real balance effect, an "intertemporal substitution effect" between 
current and future consumption which is induced by the modification of expected prices relatively to current prices (1). In particular, when the elasticity of price expectations is greater than one, the intertemporal substitution effect is likely to favour an increase of the demand for current goods, since they are now cheaper than goods available in the future. In that case, the intertemporal substitution effect typically weakens the real balance effect. Conversely, when the elasticity of price expectations is less than unity, the intertemporal substitution effect is likely to reinforce the real balance effect.

The fallowing example provides a simple illustration of the properties of short run demand functions. Let us assume that there is only one real good $(l=1)$, and consider a typical consumer who is planning for the current period and the next one only. If current and expected prices are $p_{1}$ and $p_{2}$, the consumer's current and expected budget constraints are (dropping the subscript a for simplicity) :

$$
\begin{aligned}
& p_{1} c_{1}+m_{1}=p_{1} e_{1}+\bar{m} \\
& p_{2} c_{2}+m_{2}=p_{2} e_{2}+m_{1}
\end{aligned}
$$

It is convenient to rewrite these constraints by eliminating the variables $m_{1}$ and $m_{2}$. By adding the two equalities and by taking into account the fact that $m_{2} \geqq 0$, one gets :

$$
P_{1} c_{1}+P_{2} c_{2} \leqq p_{1} e_{1}+p_{2} e_{2}+\bar{m}
$$

(1) We ignore in this heuristic discussion, for the sake of simplicity, the complications which arise from possible modifications of relative current prices and/or of relative expected prices. 
The fact that $m_{1}$ must be nonnegative yields :

(ii)

$$
p_{1} c_{1} \leqq p_{1} e_{1}+\bar{m}
$$

The optimum current and future consumptions of the agent are thus obtained by maximizing the utility function $u\left(c_{1}, c_{2}\right)$ under the two constraints $(i)$ and $(i i)$. The associated demand for money is then given by $m_{1}=\bar{m}+p_{1} e_{1}-p_{1} c_{1}$.

The consumer's opportunity set described by the constraints (i) and ( $i$ ), as well as the result of the utility maximization are pictured in Fig. 1, in the plane $\left(\mathrm{c}_{1}, \mathrm{c}_{2}\right)$. There, the line going through the points $\alpha$ and $\beta$ represents the two periods budget constraint (i), while the vertical Iine By represents the constraint (ii).

\section{Fig. 1}

It is immediate to verify on the diagram the Absence of Money Illusion property stated in (1) of this section. Consider a change of $\bar{m}, p_{1}, p_{2}$ in $\lambda \bar{m}, \lambda p_{1}$ and $\lambda p_{2}$. The change leaves obviously unaltered the coordinates of the points $\alpha$ and $\beta$. This means that the opportunity set described by $(i)$ and $(i i)$ is unchanged. The optimum values of $\mathrm{c}_{1}$ and $\mathrm{c}_{2}$ are accordingly the same. This is exactly what was stated in (1) of this section. 
$-21-$

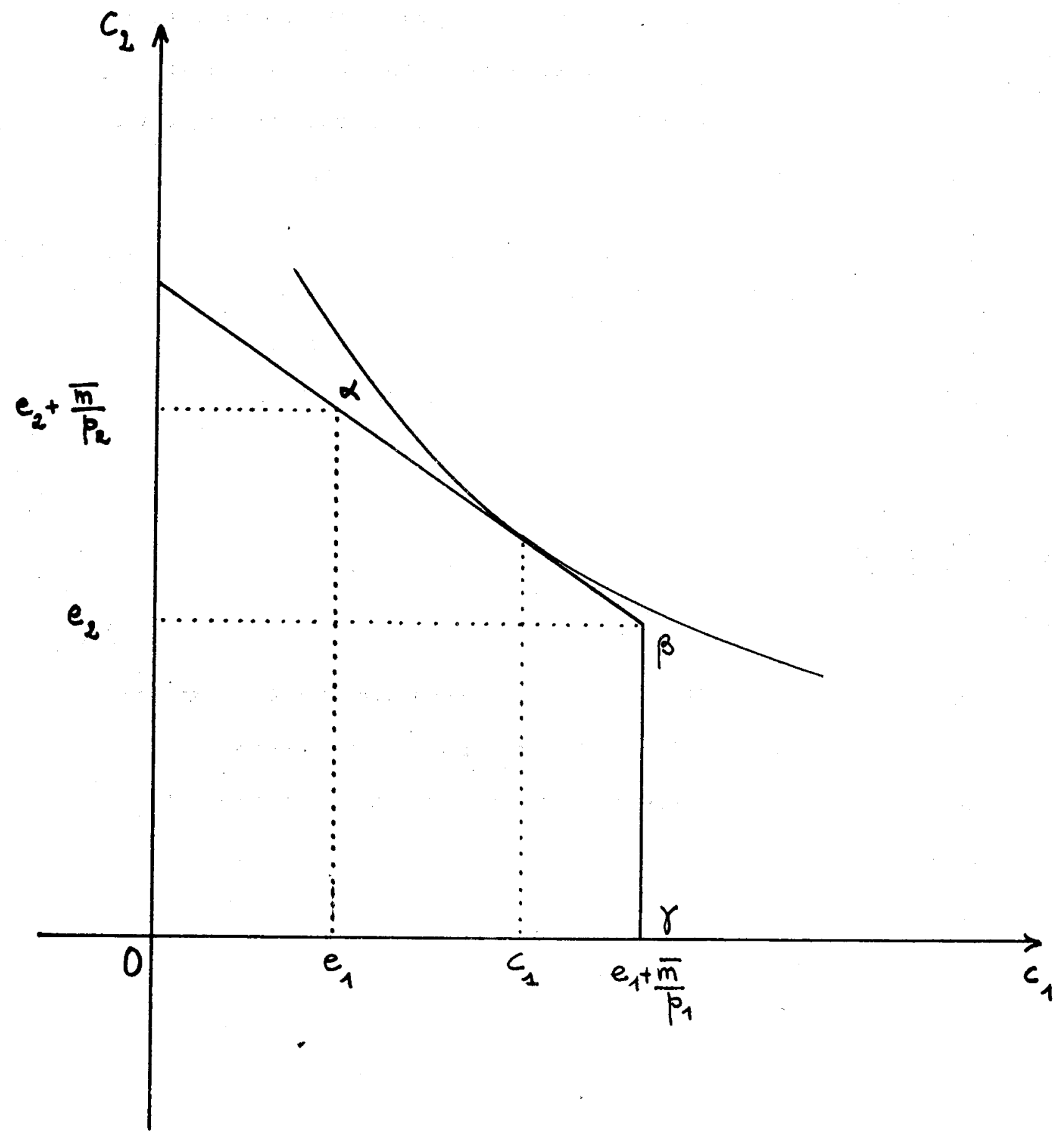

Fig. 1 
We consider next the consequence on current consumption of a change of the current price. Let $z\left(p_{1}, p_{2}, \bar{m}\right)$ be the excess demand for current consumption $\mathrm{c}_{1}-\mathrm{e}_{1}$, which arises from the above maximizing problem. It is reasonable to assume that $z$ is increasing with the initial money stock $\bar{m}$, decreasing with the current price $p_{1}$, and increasing with the expected price $\mathrm{p}_{2}$.

$$
\text { Consider now a small increase of } p_{1} \text {, say } \Delta p_{1}>0 \text {, and the }
$$
induced change of the expected price $\Delta \mathrm{p}_{2}$. If the excess demand function $z$ is differentiable, the resulting variation $\Delta z$ of current excess demand is approximately equal to :

$$
\Delta z=\frac{\partial z}{\partial p_{1}} \Delta p_{1}+\frac{\partial z}{\partial p_{2}} \quad \Delta p_{2}
$$

In order to separate the real balance effect from the intertemporal substitution effect, let us write $\Delta \mathrm{p}_{2}$ as $\Delta \mathrm{p}_{2}^{\prime}+\Delta \mathrm{p}_{2}^{\prime \prime}$, where $\Delta \mathrm{p}_{2}^{\prime}$ corresponds to an increase of $p_{2}$ proportional to the increase of $p_{1}$, that is :

$$
\frac{\Delta p_{2}^{\prime}}{p_{2}}=\frac{\Delta p_{1}}{p_{1}}
$$

The variation $\Delta z$ of excess demand becomes then : 


$$
\Delta z=\frac{\partial z}{\partial p_{1}} \Delta p_{1}+\frac{\partial z}{\partial p_{2}} \Delta p_{2}^{\prime}+\frac{\partial z}{\partial p_{2}} \Delta p_{2}^{\prime \prime}
$$

or

$$
\Delta z=\left(\frac{\partial z}{\partial p_{1}} p_{1}+\frac{\partial z}{\partial p_{2}} p_{2}\right) \frac{\Delta p_{1}}{p_{1}}+\frac{z}{\partial p_{2}} \quad \Delta p_{2}^{\prime \prime}
$$

The first term corresponds to the real balance effect associated with a proportional increase of current and expected prices. It can be expressed equivalently as the effect upon current consumption of a decrease $\Delta \bar{m}$ of the initial money stock $\bar{m}$, current and expected prices being fixed, which would be proportional to $\frac{\Delta p_{1}}{p_{1}}$, i.e., $\Delta \bar{m}=-\bar{m} \frac{\Delta p_{1}}{p_{1}}$. Indeed, the Absence of Money Illusion property states that $z$ is homogenous of degree 0 . By Euler's condition, the expression between the parentheses is equal to $-\frac{\partial z}{\partial \bar{m}} \bar{m}$. The term measuring the real balance effect is therefore equal to $\frac{\partial z}{\partial \bar{m}} \Delta \bar{m}$. It is negative since $\Delta \bar{m}$ is negative.

The second term $\frac{\partial z}{\partial p_{2}} \Delta p_{2}^{\prime \prime}$ measures the intertemporal substitution effect due to the modification of the relative prices of current and future consumption. It is positive when the elasticity of price expectations is greater than unity, since then $\Delta p_{2}^{\prime \prime}>0$. In that case, the intertemporal substitution effect.weakens the real balance effect. On the other hand, the intertemporal substitution effect is negative, and thus reinforces the real balance effect, when the elasticity of price expectations is less than unity, for then, $\Delta p_{2}^{\prime \prime}<0$. 
This decomposition between a real balance effect and an intertemporal substitution effect is easily visualized by using Figure 1. When price expectations are unit elastic, an increase of the current price $p_{1}$ causes a horizontal displacement towards the left of the lines $\alpha \beta$ and $\beta \gamma$, the slopes of these lines being unchanged. This leads to a pure income or real balance effect. When price expectations are not unit elastic, there is in addition a rotation of the intertemporal budget line $\alpha \beta$ around the point $\beta$, downwards if the elasticity exceeds one, upwards if the elasticity is less than unity. This rotation generates the intertemporal substitution effect. 
4. THE EXISTENCE OF A SHORT RUN WALRASIAN EQUILIBRIUM.

A short run Walrasian equilibrium in period 1 obtains when the current price system $p_{1}$ achieves equality of supply and demand in the goods and the money markets. By taking into account the demand functions $z_{a}\left(p_{1}, \bar{m}_{a}\right)$ and $m_{a}^{d}\left(p_{1}, \bar{m}_{a}\right)$ constructed in section 3 , this leads us to define a Walrasian equilibrium price system as a solution of a system of equations like $(C)$ and $(D)$ of section 1 :

$$
\begin{aligned}
& \sum_{a} z_{a}\left(p_{1}, \bar{m}_{a}\right)=0 \\
& \sum_{a} m_{a}^{d}\left(p_{1}, \bar{m}_{a}\right)=\sum_{a} \bar{m}_{a}
\end{aligned}
$$

displaying similar properties, except for the fact that we did not assume any specific homogereity properties.

Patinkin's remarks about the invalidity of the classical Dichotomy in short run apply equally well here, since by Walras Law any solution of $(C)$ fulfills $(D)$ : the equilibrium of the real sector determines not only relative prices, but also the level of money prices. But the main question is to find the conditions under which this system of equations has indeed a solution.

In order to study this problem, it is most convenient to look at the simple case where there is only one good $(l=1)$, so that equations, (C) and (D) are in fact equivalent. The usual argument to assert the existence of a solution to this system goes as follows: 
(i) if the price $p_{1}$ is low enough, there is an excess demand for the good (or equivalently an excess supply for money),

$$
\text { (ii) if conversely } p_{1} \text { is large, there is an excess supply }
$$
of the good (equivalently, an excess demand for money).

Then, by continuity, there would exist a value of $p_{1}$ achieving equilibrium on both markets.

Neoclassical monetary theorists usually claim that the real balance effect is strong enough in the present context to bring about the above properties of the aggregate excess demand function. According to this viewpoint, when $p_{1}$ is low, the purchasing power of the agents' initial money stocks is large, so that an excess demand should appear on the good market. If $\mathrm{p}_{1}$ is large, the purchasing power of the initial money stocks is low, and there should be an excess supply of the good.

We shall see that this argument is wrong, and that the real balance effect is typically too weak to equilibrate the market even in the most favourable case where it is the sole regulating mechanism of the economy, that is, when price expectations are unit elastic. What is actually needed is a strong intertemporal substitution effect in order to reibforce it.

In order to see more precisely this point, let us consider the simple example given in Section 3, where there is only one good and where every consumer is planning only one period ahead. The choices open to a typical agent were represented in the plane $\left(c_{1}, c_{2}\right)$ in Figure 1 , which is reproduced here. 


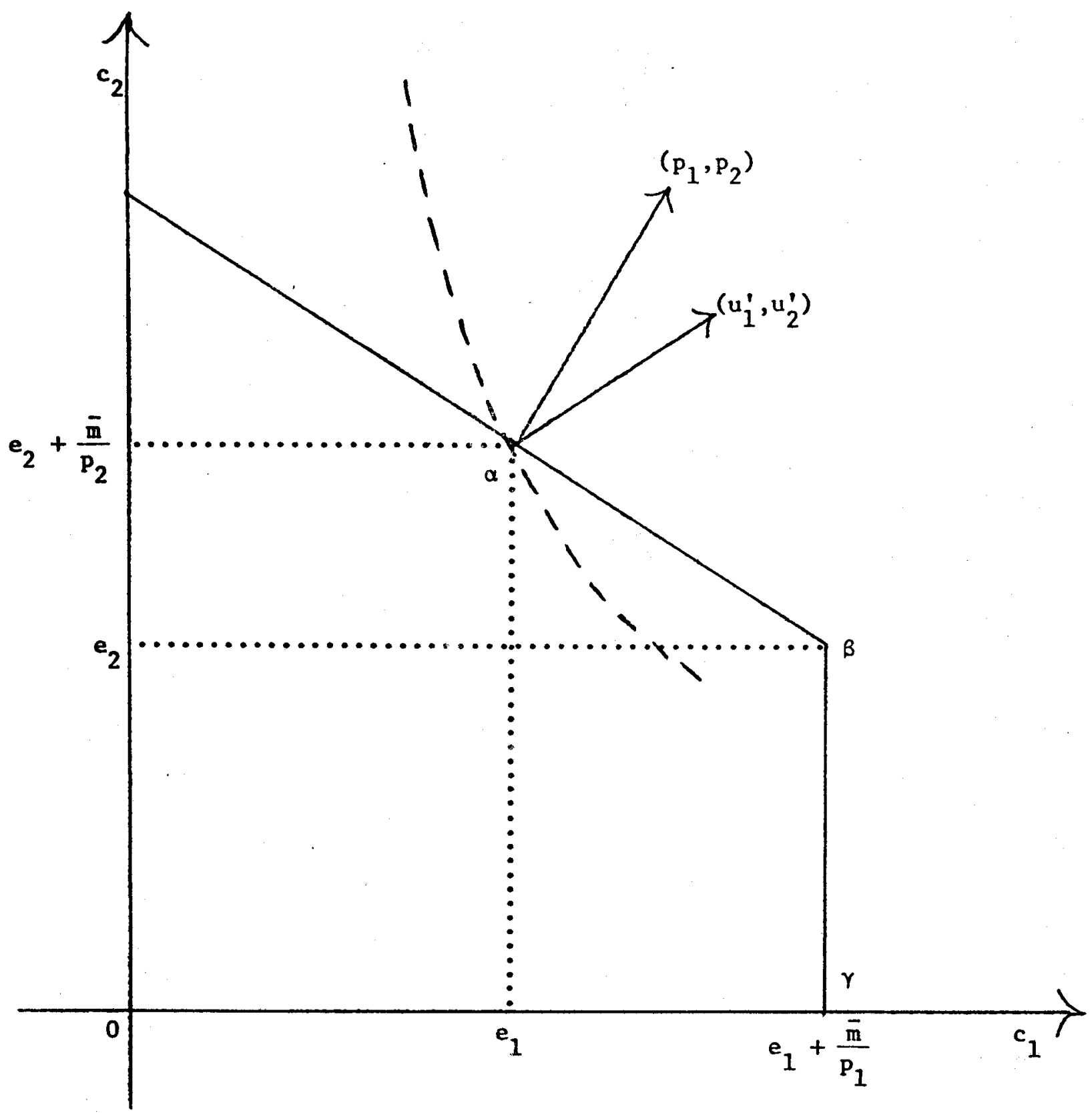

Fig. 2 
It is cleer from the diagram that the agent's demand for current consumption $c_{1}$ will exceed his endowment $e_{1}$ if and only if the slope of the normal to the intertemporal budget line $\alpha \beta$, that is $\frac{P_{2}}{P_{1}}$, exceeds the marginal rate of substitution $\frac{u_{2}^{\prime}}{u_{1}^{\prime}}$, evaluated at the point $\alpha$ (1). If we assume that a typical trader's utility function can be written $w\left(c_{1}\right)+\delta w\left(c_{2}\right)$ where $w$ is strictly concave and differentiable, and $\delta$ is a parameter between 0 and 1 , this fact can be expressed by :

$$
c_{1}-e_{1}>0 \text { if and only if } \frac{p_{2}}{p_{1}}>\delta \frac{w^{\prime}\left(e_{2}+\frac{\bar{m}}{p_{2}}\right)}{w^{\prime}\left(e_{1}\right)}
$$

It is quite easy by using this simple fact to design examples where there is a persistent disequilibrium on the good market for all values of the current price $p_{1}$.

Example 1 : Persistent excess demand.

Assume that a typical trader's expectations are biased upwards, so that the ratio $\frac{P_{2}}{P_{1}}$ is greater than or equal to the marginal rate of substitution at the endowment point $\left(e_{1}, e_{2}\right)$, that is, $\frac{p_{2}}{p_{1}} \geqq \delta \frac{w^{\prime}\left(e_{2}\right)}{w^{\prime}\left(e_{1}\right)}$ for all $p_{1}$. Since $w^{\prime}$ is a decreasing function. the trader's demand for consumption $c_{1}$ will then always exceed his endowment $e_{1}$. If all traders' expectations are biased upwards in this way, there will be an aggregate excess demand on the good market at all values of the current price $p_{1}$, and no short run Walrasian equilibrium where money has positive value can exist.

(1) It is assumed for the simplicity of the argument that every agent's money endowment $\bar{m}$ is positive. 
The phenorienon just described may occur in particular when price expectations are unit elastic with respect to the current price, that is, when the ratio $\frac{p_{2}}{p_{1}}$ is independent of $p_{1}$. The real balance effect is then the sole regulating mechanism of the economy, but it is too weak to bring the market into equilibrium. This conclusion can be valid for small expectationa? "inflationary bias", since the ratio $\frac{\mathrm{P}_{2}}{\mathrm{P}_{1}}$ need not be very large. In particular, the phenomenon occurs in the case of static expectations $\left(p_{2}=p_{1}\right.$ for every $\left.p_{1}\right)$, if the marginal rate of substitution at the endowment point is less than or equal to 1.

Example 2 : Persistent excess supply.

A similar story can be told in the case of "deflationary" expectations. Assume for instance that the marginal rate of substitution evaluated at various points of the vertical line going through the endowment point. in Figure 2, is bounded below by some positive number $v$. If the consumer's expectations are biased downwards, so that $\frac{P_{2}}{P_{1}}<\nu$ for every $P_{1}$, the agent's demand for current consumption $c_{1}$ is less than his endowment $e_{1}$ for every $p_{1}$. If all traders' price expectations are biased downwards in this way, there is an aggregate excess supply on the good market for all values of the current price system $\mathrm{p}_{1}$, and no short run Walrasian equilibrium can exist. Again, the phenomenon can occur when price expectations are unit elastic with respect to the current prices. The real balance effect, which is then the only regulating mechanism of the economy, is too weak in that case to equilibrate the market. 
Many other examples can be designed along these lines. For instance, consider a utility function of the type $c_{1}^{\lambda}+\delta c_{2}^{\lambda}$, where $\lambda$ and $\delta$ are parameters between $\square$ and 1 . Then straightforward computations show that $c_{1}-s_{1}>0$ if and only if $p_{1}<f\left(p_{2}\right)$ where

$$
f(p)=\frac{1}{\delta e_{1}^{1-\lambda}} p^{\lambda}\left(p e_{2}+\bar{m}\right)^{1-\lambda} .
$$

The function $f$ increases from 0 to infinity when $p$ varies from 0 to infinity, and therefore has an inverse. Then an excess demand on the good market will exist at all current prices $p_{1}$ if $p_{2}>f^{-1}\left(p_{1}\right)$ for every $p_{1}$, an excess supply if $p_{2}<f^{-1}\left(p_{1}\right)$ for all $p_{1}$.

These examples can of course be transposed to the case of several goods. For instance, consider the case where a typical trader's utility function is of the form $w\left(c_{1}\right]+\delta w\left(c_{2}\right)$ where $w$ is strictly concave and $\delta$ between 0 and 1 . Assume moreover that the trader's real income is constant over time $\left(e_{1}=e_{2}\right\}$ and that he has static expectations $\left(p_{2}=p_{1}\right)$. It is then straightforward to check that the value of the trader's excess demand for current consumption, $\mathrm{P}_{1}\left(\mathrm{c}_{1}-\mathrm{e}_{1}\right)$, always exceeds $\frac{\bar{m}}{\overline{2}}$. If all traders satisfy these conditions, the goods markets cannot be brought simultaneously into equilibrium. The reader will easily design other examples along these lines.

These examples show that the real balance effect is typically too weak, and that it must be reinforced by a strong intertemporal substitution effect if one wishes to be able to equilibrate the market. As we shall see, this essentially requires in the present model that the expected prices of at least one agent be substantially insensitive to current prices. 
To verify this point, let us return to the simple case where there is only one good and where all agents are planning only one period ahead. In order that an excess supply appears on the good market when its price $p_{1}$ is large, one must impose a condition on expectations which prevents the occurance of the phenomenon described in the first example. Money balances being necessarily nonnegative, every agent's excess demand for the good, $c_{1}-e_{1}$, must not exceed $\frac{\bar{m}}{p_{1}}$, which tends to zero as $p_{1}$ tends to infinity. It suffices therefore that the demand $c_{1}$ of at least one agent becomes eventually less than his endowment $e_{1}$ in order that an excess supply appears on the good market at the aggregate level. What is needed here is a strong intertemporal sutstitution effect which favors future against current consumption. This will be achieved if the expected price $\mathrm{P}_{2}$ of at least one agent is bounded above when $p_{1}$ tends to infinity. Indeed, if we look at Figure 2, and if we assume for simplicity that $P_{2}$ is actually fixed independently of $P_{1}$, this agent's intertemporal budget line rotates around the point $\alpha$ and becomes steeper and steeper as $\mathrm{p}_{1}$ increases. Substitution between future and current consumption generates ultimately an excess supply on the good market.

$$
\text { Symetricaliy, one needs a condition on expectations which }
$$
excludes the phenomenon described in the second example if one wishes an excess demand to appear on the good market when its price $p_{1}$ is low. Here, what is needed is a strong intertemporal substitution effect which favors current consumption. Such a condition is that the expected price $\mathrm{p}_{2}$ of at least one agent with a positive money stock $\bar{m}$, is bounded below by some positive number as $p_{1}$ tends to zero. To verify this claim, it suffices to look at Figure 2. Assume, again for simplicity, that $p_{2}$ 
is actually fixed independently of $\mathrm{p}_{1}$. Then the agent's intertemporal budget line rotates around the point $\alpha$ and becomes more and more horizontal as $p_{1}$ decreases : the intertemporal substitution effect favors more and more current consumption relatively to future consumption. Since $\bar{m}$ is positive, the agent's demand for current consumption actually goes to infinity, and this is sufficient to generate an excess demand on the good market at the aggregate level.

In order to describe a formal result along this line on the existence of a short run equilibrium, we introduce a few definitions. Let us say that whenever $n_{a} \geqq 2$, agent a's price expectations are continuous if the functions $\psi_{\text {at }}\left(p_{1}\right)$ are continuous in $p_{1}$, for every t. An agent's price expectations are said to be bounded if there are two vectors $\varepsilon$ and $\eta$, with all their components positive, such that $\varepsilon \leqq \psi_{a t}\left(p_{1}\right) \leqq n$ for every current price system $p_{1}$ and every $t$. The last condition ensures the presence of a strong intertemporal substitution effect which reinforces the real balance effect, and is the key condition for the following existence theorem (1).

(1) Assume (a), (b) ana' (c) of Section 2. Assume moreover that every agent's price expectations are continuous, and that there is at least one-agent $a$, with $n_{a} \geqq 2$ and $\bar{m}_{a}>0$, whose price expectations are bounded. Then, there exists a short run walrasian equilibrium.

(1) A formal proof of the theorem is given in Appendix $B$. 
The general idea which underlies this result and the arguments which led to it, is that one needs a strong intertemporal substitution effect which reinforces the real balance effect in order to be sure of the existence of a short run equilibrium. This essentially requires that some agent's price forecast display a substantial degree of insensitivity to large variations of current prices. The insensitive traders are then there to act as a flywheel, and to stabilize the market process. That such conditions can be met in actual market economies is hardly to be expected. Price forecasts are indeed somewhat volatile, and are presumably quite sensitive to the level of current prices, especially in periods of inflation or deflation. In particular, expectations are likely to be biased upwards in the case of inflation, and downwards in the case of deflation. The examples which we gave show that a short run equilibrium typically does not exist in such circumstances. The general conclusion which emerges from this analysis is accordingly that the existince of a short run walrasian equilibrium where money has positive value is somewhat problematic in actual market economies, contrarily to what neoclassical economists used to believe.

Remark. We have focused the attention in this discussion on short run equilibria where money has positive value. Under assumptions (a) and (b) of Section 2, it can be shown that there are nonmonetary equilibria where money has no value in this economy. They are characterized by the fact that there are no income transfers over time. For instance, if there is only one good $(l=1)$, a nonmonetary equilibrium is the autarkic one, where every trader consumes his own endowment of good in each period. 


\section{THE EXPECTED UTIIITTY OF MONEY.}

It is common practice among monetary theorists to write down for each agent a utility function depending on consumption and "real" balances, on the ground that money for instance renders services as a liquid asset and a medium of exchange. Short run demand functions are then obtained as the result of maximizing such utility functions under the relevant budget constraints. The aim of this section is to describe a method of general applicability which justifies this procedure, provided that the indirect utility of money balances is correctly derived.

Consider again a typical consumer (dropping his subscript a for convenience) who is faced in period 1 by a price system $p_{1}$. We are trying to construct an index which would describe his preferences among current consumption $c_{1} \geqq 0$ and money balances $m_{1} \geqq 0$. Since $m_{1}$ represents a stock, the usefulness of which depends on its purchasing power in the future, such an.index will certainly depend upon expected prices, and thus on current prices in as much they determine price expectations. More precisely, consider the maximum level of utility that the consumer can expect to achieve over the remaining of his lifetime if he chooses now $c_{1}$ and $m_{1}$. This is the result of the following decision problem :

Given $c_{1} \geqq 0, m_{1} \geqq 0$ and $p_{1}$, maximize $u\left(c_{1}, c_{2}, \ldots, c_{n}\right]$ with respect to $\left(c_{2}, \ldots, c_{n}\right) \geqq 0$ and $\left(m_{2}, \ldots, m_{n}\right) \geqq 0$, subject to the expected budget constraints :

$$
\psi_{t}\left(p_{1}\right) c_{t}+m_{t}=\psi_{t}\left(p_{1}\right) e_{t}+m_{t-1},(t=2, \ldots, n) .
$$


The maximum value of the utility function depends upon $c_{1}, m_{1}$ and on current prices through their influence on price expectations (and implicitly on past history, as well as on future real incomes $)$. Let $v\left(c_{1}, m_{1}, p_{1}\right)$ be this maximum. It can be interpreted as the expected utility of $\left(c_{1}, m_{1}\right)$ when the price system $p_{1}$ is currently quoted.

This expected utility $v\left(c_{1}, m_{1}, p_{1}\right)$ is indeed the index we were looking for. It is in fact easy to verify :

$$
\text { Maximizing } v\left(c_{1}, m_{1}, p_{1}\right) \text { with respect to } c_{1} \geqq 0 \text { and } m_{1} \geqq 0
$$
subject to the current budget constraint $p_{1} c_{1}+m_{1}=p_{1} e_{1}+\bar{m}$, yields an excess demand $c_{1}-e_{1}$ and a demand for money $m_{1}$ which are equal to $z\left(p_{1}, \bar{m}\right)$ and $m^{d}\left(p_{1}, \bar{m}\right)$.

In order to prove this proposition, consider the unique solution of Problem (II) of Section $3,\left(c_{1}^{*}, \ldots, c_{n}^{*}\right)$ and $\left(m_{1}^{*}, \ldots, m_{n}^{*}\right)$. One has by definition, $c_{1}^{*}-e_{1}=z\left(p_{1}, \bar{m}\right), m_{1}^{*}=m^{d}\left(p_{1}, \bar{m}\right)$ and $p_{1} c_{1}^{*}+m_{1}^{*}=p_{1} e_{1}+\bar{m}$. Moreover, future consumptions $\left(c_{2}^{*}, \ldots, c_{n}^{*}\right)$ and money holdings $\left(m_{2}^{*}, \ldots, m_{n}^{*}\right)$ achieve the maximum of $u\left(c_{1}^{*}, c_{2}, \ldots, c_{n}\right)$ given $c_{1}^{*}$ and $m_{1}^{*}$, when $\left(c_{2}, \ldots, c_{n}\right),\left(m_{2}, \ldots, m_{n}\right)$ vary subject to the expected bujget constraints $\psi_{t}\left(p_{1}\right) c_{t}+m_{t}=\psi_{t}\left(p_{1}\right) e_{t}+m_{t-1}$, $(t=2, \ldots, n)$ where by convention $m_{1}=m_{1}^{*}$. Therefore, by definition of the expected utility:

$$
u\left(c_{1}^{*}, \ldots, c_{n}^{*}\right)=v\left(c_{1}^{*}, m_{1}^{*}, p_{1}\right)
$$


Consider now other values of current consumption and of money holdings, $\left(c_{1}, m_{1}\right)$, which differ from $\left(c_{1}^{*}, m_{1}^{*}\right)$ and fulfill the current budget constraint, $p_{1} c_{1}+m_{1}=p_{1} e_{1}+\bar{m}$. Note that this implies necessarily that $c_{1}$ is different from $c_{1}^{*}$. One can associate to $\left(c_{1}, m_{1}\right)$ the solution $\left(c_{2}, \ldots, c_{n}\right),\left(m_{2}, \ldots, m_{n}\right)$ of Problem (III). By definition of the expected utility index,

$$
u\left(c_{1}, \ldots, c_{n}\right)=v\left(c_{1}, m_{1}, p_{1}\right) .
$$

Since the program $\left(c_{1}, \ldots c_{n}\right),\left(m_{1}, \ldots, m_{n}\right)$ fulfills the constraints of Problem (II) of Section 3 , and since $c_{1}^{*}$ differs from $c_{1}$, one must have

$$
u\left(c_{1}^{*}, \ldots, c_{n}^{*}\right)>u\left(c_{1}, \ldots, c_{n}\right),
$$

or equivalently,

$$
v\left(c_{1}^{*}, m_{1}^{*}, p_{1}\right)>v\left(c_{1}, m_{1}, p_{1}\right)
$$

which proves the claim.

The above construction of the expected utility index $v\left(c_{1}, m_{1}, p_{1}\right)$ justifies accordingly the "introduction of money balances in the utility function". Current prices enter the utility function too, since they determine price expectations. We can thus discuss precisely the validity of the neoclassical claim, stating that "only real money balances enter the utility function". The natural counterpart of this statement in the present context would be to say that the expected 
utility index $v\left(c_{1}, m_{1}, P_{1}\right)$ is homogenous of degree 0 with respect to money balance $m_{1}$ and current price $p_{1}$. If we had let expected prices $p_{2}, \ldots, p_{n}$ to vary independently of the current price system $p_{1}$ in Problem (III), we would have obtained an expected utility index $v$ depending upon $c_{1}, m_{1}$ and the sequence $p_{2}, \ldots, p_{n}$ of expected prices, which would háve been indeed homogenous of degree 0 in the money balance $m_{1}$ and expected prices $p_{2} \ldots, p_{n}$. But once the dependence of price expectations upon current prices is recognized, the conclusion is that $v\left(c_{1}, m_{1}, p_{1}\right)$ is not in general homogenous of degree 0 with respect to $\left(m_{1}, p_{1}\right)$ unless price expectations are unit elastic with respect to current prices. This conclusion is the analogue of results (1) and (2) of Section 3 on short run demand functions.

It might be useful to illustrate the concept of an expected utility index by means of an example. Let us consider the case where there is only one real good, $(l=1)$, and where the typical consumer plans for the current period and the next one only $(n=2)$. If the consumer's money balance is $m_{1}$, and if his price forecast is $\psi\left[p_{1}\right]$, he has no freedom of choice in the future, since his consumption $c_{2}$ must equal then $e_{2}+\frac{m_{1}}{\psi\left(p_{1}\right)}$. In that case, the expected utility index is :

$$
v \quad v\left(c_{1}, m_{1}, p_{1}\right)=u\left(c_{1}, e_{2}+\frac{m_{1}}{\psi\left(p_{1}\right)}\right) .
$$

Since the expression $\frac{m_{1}}{\psi\left(p_{1}\right)}$ can be rewritten $\frac{m_{1}}{p_{1}} \frac{p_{1}}{\psi\left(p_{1}\right)}$, the expected utility index $v$ can be viewed as a function of the current consumption $c_{1}$ and the "real balance" $\frac{m_{1}}{p_{1}}$, and of the current 
price $p_{1}$ in as much it determines the ratio $\frac{\psi\left(p_{1}\right)}{p_{1}}$. Therefore, given $\mathrm{P}_{1}$, the expected utility index defines a set of indifference curves in the plane $\left(c_{1}, \frac{m_{1}}{p_{1}}\right)$ which have the usual shape, as shown in Fig. 3.a. (1)

It is useful to examine at this stage the effect upon the indifference curves of, say, an increase of the current price from $p_{1}$ to $\mathrm{P}_{1}^{\prime}$. Consider an indifference curve corresponding to a given level of the expected utility index before that the increase of the current price has taken place (see the plain curve in Fig. 3.b). The new indifference curve associated to the same level of utility is then obtained by applying an affine transformation to the old one, using the axis $\overrightarrow{O c_{1}}$ and the ratio $\lambda=\frac{\psi\left(p_{1}^{\prime}\right)}{p_{1}^{\prime}} \frac{p_{1}}{\psi\left(p_{1}\right)}$ (see the dotted curve in Fig. 3.b). In the Neoclassical case, that is, when price expectations are unit elastic, $\lambda$ is equal to 1 , and the indifference curves are unaltered. But when the elasticity of price expectations is greater than unity, for instance, the increase of the current price leads to an "upward affine transformation" of the indifference curves, since then $\lambda$ is greater than 1. The transformation takes place in the other direction otherwise.

Fig. 3.a Fig. 3.b

(1) The reader will easily check that such indifference curves typically cut the axis $\overrightarrow{0 \vec{c}}_{1}$ at some point. This fact requires that for any current and future consumption $\left(c_{1}, c_{2}\right)$, with $c_{1}>0$ and $\mathrm{c}_{2} \geqq \mathrm{e}_{2}$, there exists a level of current consumption $c_{1}^{\prime}$ such that $u\left(c_{1}^{\prime}, e_{2}\right)>u\left(c_{1}, c_{2}\right)$, which is a quite reasonable condition. 

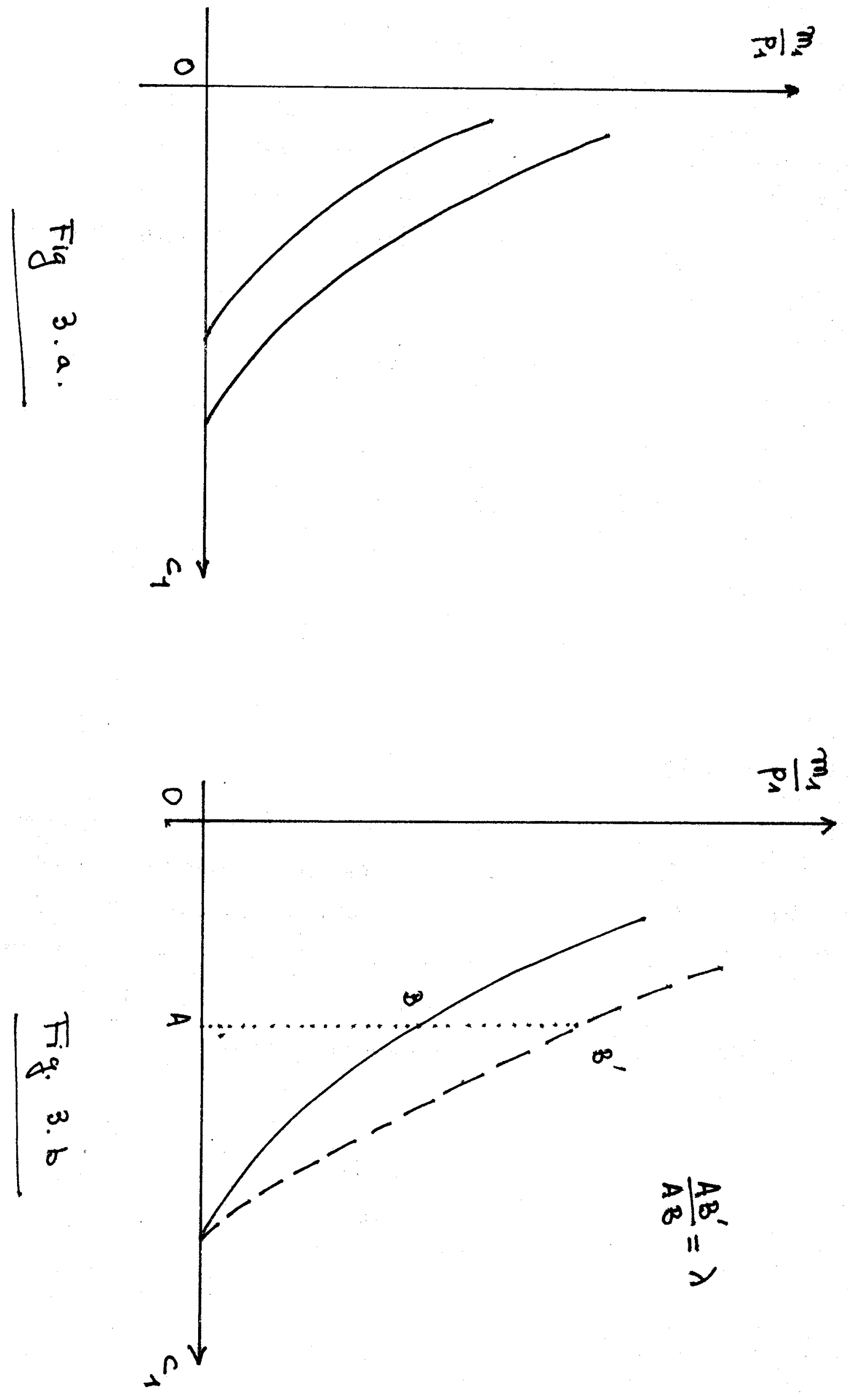
The result stated in (1) of the present Section is obvious in this simple case : given $p_{1}$, the trader's optimum consumption $c_{1}$ and real balance $\frac{m_{1}}{p_{1}}$ is obtained by maximizing the expected utility index subject to the current budget constraint. This budget constraint can be written :

$$
c_{1}+\frac{m_{1}}{p_{1}}=e_{1}+\frac{\bar{m}}{p_{1}}
$$

and is thus represented in the plane $\left(c_{1}, \frac{m_{1}}{p_{1}}\right)$ by a line which is perpendicular to the vector $(1,1)$ and goes through the point $\left(e_{1}, \frac{\bar{m}}{p_{1}}\right)$. The result of the maximization of the expected utility index is shown in Fig. 4.

\section{Fig. 4}

It is clear from this diagram that whenever $\vec{m}$ is positive, the trader's optimum consumption $c_{1}$ exceeds his endowment $e_{1}$ if and only if the marginal rate of substitution between real balance and consumption evaluated at the point $\left(e_{1}, \frac{\bar{m}}{p_{1}}\right)$ is less than 1 . When the utility function $u$ is of the form $w\left(c_{1}\right)+\delta w\left(c_{2}\right)$ where $w$ is strictly concave, differentiable, and where $\delta$ is a parameter between 0 and 1 , this condition reads :

$$
\delta \frac{p_{1}}{\psi\left(p_{1}\right)} \frac{w^{\prime}\left(e_{2}+\frac{\bar{m}}{\psi\left(p_{1}\right)}\right)}{w^{\prime}\left(e_{1}\right)}<1 .
$$


- $41-$

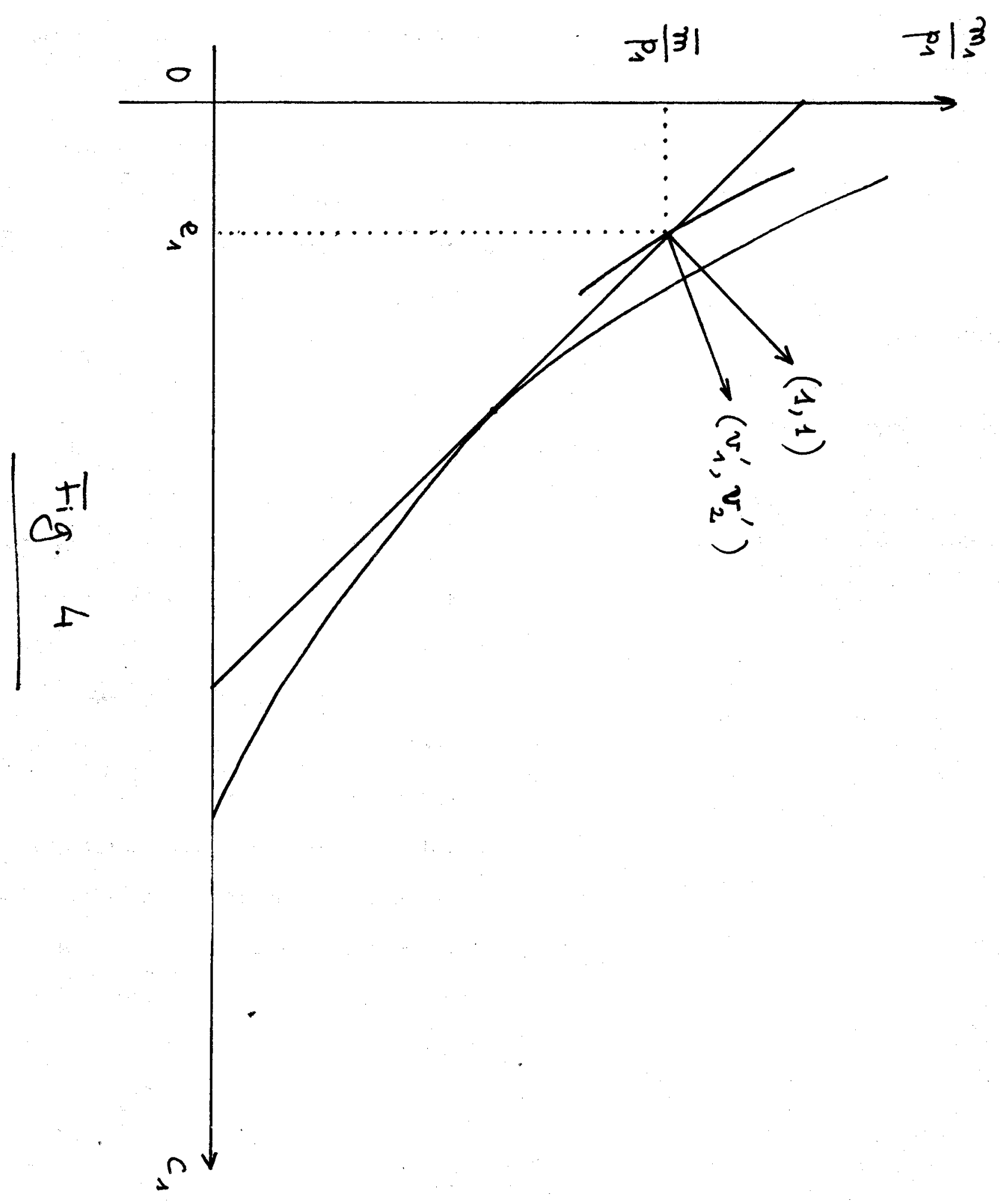


This is of course the same condition which was obtained in the previous Section when analysing directly the trader's intertemporal optimization program.

The relative impacts of the real balance and of the intertemporal substitution effects, which were discussed in Section 3, appear quite clearly on the diagram too. Consider an increase of the current price from $p_{1}$ to $p_{1}^{\prime}$. The budget line moves then down since it goes now through the point $\left(e_{1}, \frac{\bar{m}}{p_{1}^{\prime}}\right)$ (Fig. 5). If price expectations were unit elastic, the indifference curves in the plane $\left(c_{1}, \frac{m_{1}}{p_{1}}\right)$ would be unchanged, and the trader's optimum mix of consumption and real balance would move from $A$ to $A^{\prime}$, as shown in Fig. 5. This move corresponds to the real balance effect, which is a pure "income effect", and thus is likely to reduce both the demands for current consumption and for real balances. But when price expectations are not unit elastic, indifference curves are modified in the way which we described above. The point representing the trader's optimum decision moves accordingly from $A^{\prime}$ to, say, $A$ " on the new budget line (see Fig. 5). This move corresponds to the intertemporal substitution effect. When the elasticity of price expectations exceeds 1, there is an upward affine transformation of the indifference curves. The intertemporal substitution effect is thus likely to lead to an increase of current consumption in that case, and thus to counteract the real balance effect. 
$-43-$

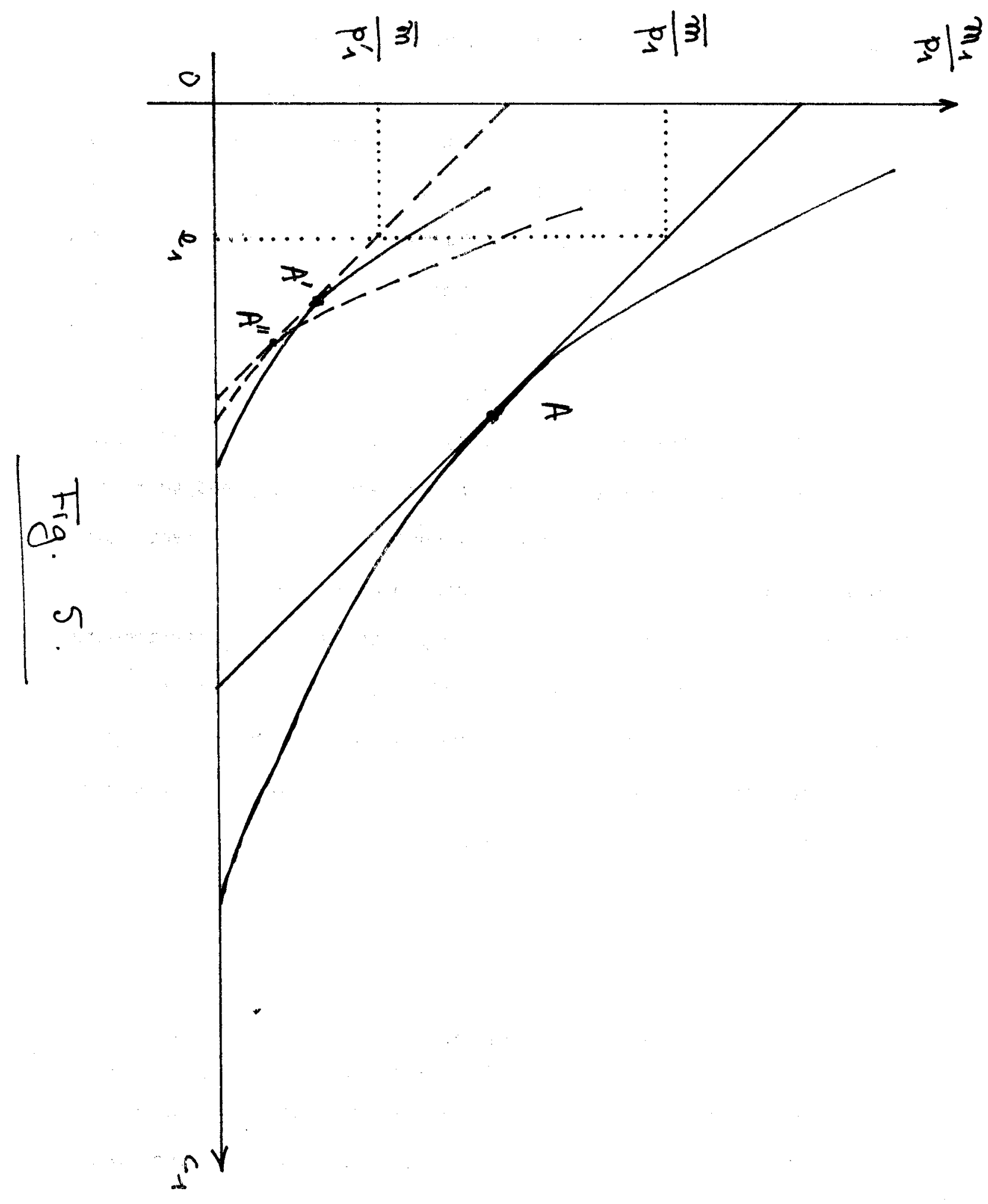


To conclude, the arguments developed in this Section show that "the introduction of money balances in a trader's utility function" is a valid procedure, provided however that the utility of money is derived from the trader's intertemporal decision program which lies underneath, as in Problem (III) above. Once this is done, one can of course choose to work exclusively with the resulting expected utility index, since it embodies all the information which was contained in the trader's intertemporal choice problem (1). But this analysis points to one of the great dangers of this procedure. For it is greatly tempting to start directly with a utility function which depends upon current consumption, money balance and current prices, and to forget the traders' underlying intertemporal choices. This is in fact what many Neoclassical monetarists have done, and still do. It is clear that such a neglect makes quite hard a precise study of intertemporal substitution effects, the importance of which we have stressed at length while studying market equilibrating forces. The reason why Neoclassical writers have failed to produce a satisfactory monetary theory does not seem to lie elsewhere.

(1) In this respect, an useful exercise for the reader would be to transpose the arguments developed in the previous Section about the existence of a short run Walrasian equilibrium, by using the expected utility index constructed in this Section in the plane $\left(c_{1}, \frac{m_{1}}{p_{1}}\right)$. 


\section{STATIONARY STATES.}

In order to study stationary states of the economy, we need a more detailed specification of the dynamic structure of the model.

We are working within the framework of an overlapping generation model without bequest and with a constant population. There are various "types" of agents. Agerts of type $i$ are characterized by :

(i) the number $n_{i} \geqq 2$ of periods of their lifetime,

(ii) the profile of their real income during their life, which is described by the endowment of goods $e_{i_{\tau}}$, a vector with $l$ components, which they own in the $\tau$-th period of their life, $\tau=1, \ldots, n_{i}$.

(iii) their preferences over consumption streams, which are represented by a utility function $u_{i}\left(c_{i 1}, \ldots, c_{i n_{i}}\right)$, where $c_{i \tau}$, a vector with $\&$ nonnegative components, is their consumption in the $\tau$-th period of their life.

It is assumed further that, in each period, a "newborn" agent of each type comes into the market. At the same date, an agent of each type who arrives at the end of his life leaves the market. Thus, in each period, there are $n_{i}$ agents of type $i$ who participate in market activity, each of them being in a different period of his life. The characteristics of the agents of a given type are supposed to be independent of time, that is, they are independent of the date of their "birth". 
In this context, a trader a living in a given period, say period 1, is described by his type $i$ and his "age" $\tau$ (which means that he is in the $\tau$-th period of his life). It is then easy to deduce from the characteristics of his type and from the knowledge of his past decisions (if any), the short run characteristics of this agent, as they were introduced in Section 2. Indeed $n_{a}$ is then equal to the number of periods he has still to live including the present one, i.e., to $n_{i}-\tau+1$. The utility function $u_{a}$ is obtained from $u_{i}$ by keeping fixed its $\tau-1$ first arguments at the level of the trader's past consumptions. The endowment vectors $e_{a t}$ are equal to his current and future endowments of goods. Lastly, his money balance $\bar{m}_{a}$ at the outset of the period is equal to the amount of money he decided to keep at the preceding date. Of course, $\bar{m}_{a}=0$ for a "newborn" trader $(\tau=1)$, since by assumption, there a no bequests in this model.

We shall use in the present section the following assumptions, which are natural counterparts of the assumptions made in Section 2 on the short run characteristics of every agent.

(a) The utility function $v_{i}$ is continuous, increasing and strictly quasi-concave, for every i.

(b) The endowment vectors $e_{i \tau}$ have all their components positive, for all $i$ and $\tau$.

(c) The total stock of money $M$ is positive. 
The notion of a sequence of short run equilibria is now intuitively clear. Consider this economy at a given date, say date 1. The economy's past history, in particular past equilibrium prices and the traders' past decisions, are then given. We just saw how these data determine the short run characteristics of every agent living at date 1. In order ti apply the analysis developed in Sections 3 and 4, all what is needed is to know how price forecasts are formed. This involve the specification of : (i) the information which a trader of type $i$ and of age $\tau$ has in any period about the economy's past history, and (ii) the functional relationship linking his price forecasts for the remaining periods of his life with his information on past history and with current prices. For the purpose of this study, it is not necessary however to be precise on these points. It is enough to remark that such a specification implies a relation between expected prices and current prices for every trader, and that the notion of a short run equilibrium analysed in the preceding sections applies directly here. Picking up a short run equilibrium price system at date 1 determines in particular the traders' actions at that date. One can then repeat this procedure at date 2 and so on, and define a sequence of short run equilibria in this manner.

A stafionary state in this economy is by definition a sequence of short run equilibria where prices remain constant over time. It should be emphasized that, although the analysis carried out in the previous sections casts serious doubts about the existence of a short run Walrasian equilibrium in general, stationary states are of independent interest. 
For they can arise as stationary states of dynamic processes which differ from the one which we just described, e.g., from disequilibrium processes where prices do not clear markets at every date. The aim of this Section is to show that such stationary equilibrium price systems can be obtained as solutions of a Classical system like $(A)$ and $(B)$ of Section 2 .

It is reasonable to assume that whenever a trader observes at some date that the price system has been the same in the past and in the current period, he believes that the same price system will prevail in the future (1). This assumption - which implies that traders have rational expectations along stationary states - permits a very simple derivation of the equations which must be satisfied by stationary equilibrium prices.

Indeed, along a stationary state where the price system is $p$, the consumptions $\left(c_{i \tau}\right)$ and money holdings $\left(m_{i \tau}\right)$ of a trader of type $i$ during his lifetime will be solutions of the following program :

(1) This assumption postulates implicitly that a trader's information about the past contains at least past prices. It should be noted that the assumption is a statement on the dependence of expected prices with respect to current and past prices. It is therefore compatible with conditions saying that expected prices are to some extent insensitive to, or even independent of current prices, like the conditions which were used in (1) of Section 4. 
(IV)

Maximize $v_{i}\left(c_{1}, \ldots, c_{n_{i}}\right)$ with respect to $\left(c_{1}, \ldots, c_{n_{i}}\right) \geqq 0$ and $\left(m_{1}, \ldots, m_{n_{i}}\right] \geqq 0$, subject to the budget constraints :

$$
p c_{\tau}+m_{\tau}=p e_{i \tau}+m_{\tau-1} \quad\left(\tau=1, \ldots, n_{i}\right)
$$

(with the convention $m_{0}=0$ ).

When all components of $\mathrm{p}$ are positive, (IV) has a solution which is unique. We can thus write accordingly the excess of consumption over endowments $c_{i \tau}-e_{i \tau}$ and the money stocks $m_{i \tau}$ obtained from (IV) as functions of $p$, that is, $z_{i \tau}(p)$ and $m_{i \tau}(p)$, for every $\tau$. We shall note $z_{i}(p)=\sum_{\tau} z_{i \tau}(p)$ and $m_{i}(p)=\sum_{\tau} m_{i \tau}(p)$.

Consumers forecast correctly the future along a stationary state. Accordingly, in any period, what a newborn trader plans to do in the future in the $\tau$-th period of his life is precisely what the agent of the same type and of age $\tau$ is actually doing in the same period. Therefore $z_{i}(p)$ and $m_{i}(p)$ represent the aggregate excess of consumption over endowment of goods, and the aggregate money stock of all agents of type $i$ in each period along the stationary state. It follows that $p$ is a stationary equilibrium price system if and only if it is a solution of the following equations, which express the fact that all markets clear :

(A)

$$
\begin{aligned}
& \sum_{i} z_{i}(p)=0 \\
& \sum_{i} m_{i}(p)=M
\end{aligned}
$$

where the summation sign runs over all types $i$ of agents. 
Before looking at the properties of these equations, a comment is in order. Although the equations (A) describing the stationary equilibrium of the real sector do not depend on the quantity of money, their structure depends crucially on the presence of money in the economy. Indeed, if money did not exist as a store of value, the constraints in (IV) should read $\mathrm{pc}_{t}=\mathrm{pe}_{\text {it }}$ for every $t$, which would lead to an entirely different system of equations. For instance, in the case of a single consumption good, the unique solution would be the autarkic one, $c_{i t}=e_{i t}$

We proceed now to showing that $(A)$ and $(B)$ display all the properties of the Classical system which we discussed in Section 1. First, examination of (IV) leads to the immediate conclusion that :

The functions $z_{i}(p)$ are homogenous of degree 0 , and the functions $m_{i}(p)$ are homogenous of degree 1 in prices.

As a matter of fact, this is nothing else than the Absence of Money Illusion properly stated in (1) of Section 3, since a newborn agent has no money $\left(m_{0}=0\right)$.

On the other hand, it is easy to verify that :

walras Law reduces here to 'Say's Law, that is, $p \sum_{i} z_{i}(p)=0$ for every $p$. 
Indeed, if one takes into account that it is never optimal for an agent to keep a positive money balance at the end of his life, summation of the constraints in (IV) yields $p z_{i}(p)+m_{i}(p)=m_{i}(p)$ for every $p$ and every $i$, hence, the result.

We have therefore proved that the equations $(A)$ and $(B)$ satisfy all the properties of the Classical system. The Classical Dichotomy and the quantity Theory are thus valid propositions when applied to stationary states in an economy with a constant money stock. The real sector (equations (A)) determine relative prices and real variables, independently of the quantity of money. The money sector (equation $(B)$ ) in turn determines the level of money prices and of nominal variables, which is proportional to the total money stock.

It remains to be seen whether such a system of equations has a solution under reasonable conditions. Since (A) looks like an ordinary Walrasian system, one can expect that it has a solution under standard assumptions. As a matter of fact (1),

(1) Assume (a) and (b) of the present Section. Then (A) has a solution $p$, which has all its components positive and is defined up to a positive real number.

Given any solution $\bar{p}$ of $(A)$, the level of money prices must be determined by looking at the money market equation $(B)$. Since the functions $m_{i}(p)$ are homogenous of degree 1 in prices, this is done by 
solving in $\lambda$ the equation $\sum_{i} m_{i}(\lambda \bar{p})=M$. This equation has a positive solution, which is then unique, if and only if $\sum_{i} m_{i}(\bar{p})$ is positive, or equivalently, if and only if there is a type $i$ of traders such that $m_{i}(\bar{p})>0$.

Under the assumptions of (1), the system $(A)$ and $(B)$ has $a$ solution if and only if there exists a solution $\bar{p}$ of $(A)$ such that $m_{i}(\bar{p})$ is positive, for some $i$.

The existence of stationary equilibrium will therefore be guaranteed if there is a type $i$ of agents who have enough incentives to save when the price system is stationary. Intuitively, this will be the case if they experience a fall of their income in their life, and if their preference for present consumption is not too strong.

In order to make precise this intuition, let us assume that there is a type $i$ of consumers which satisfies the following two assumptions :

(d) The utility function $u_{i}$ is of the form $\sum_{\tau} \delta_{i}^{\tau-1} w_{i}\left(c_{i \tau}\right)$, where $w_{i}$ is strictly concave and $0<\delta_{i} \leqq 1$,

(e) There are $\tau$ and $\tau^{\prime}$ with $\tau<\tau^{\prime}$ such that $e_{i \tau} \geqq e_{i \tau^{\prime}}$, with strict inequality for some component.

Our goal is to show that under these assumptions, the system $(A)$ and $(B)$ has a solution if the parameter $\delta_{i}$ is close to unity. We shall show in the first place that the result is true when there is no preference for present consumption, that is, when $\delta_{i}=1$. Then by continuity, the result is still true when $\delta_{1}$ is close to 1 . 
It is first clear that under assumptions $(d)$ and $(e), m_{i}(p)$ is positive for every stationary price system $p$ when $\delta_{i}$ is equal to 1 . The proof of this claim is quite simple. Let us suppose on the contrary that there exists a $p$ such that $m_{i}(p)=0$. This would mean that the solution of Problem (IV) associated to this specific $p$, say $\left(c_{\tau}^{*}, m_{\tau}^{*}\right.$ ), is such that $m_{\tau}^{*}=0$ for every $\tau$. This implies of course $\mathrm{pc}_{\tau}^{*}=p_{\text {, }}$ i $\tau$ for every $\tau$. But this is impossible since $p e_{i \tau}>p e_{i \tau}$. . As a matter of fact, the consumption program which is obtained by replacing ${ }_{C_{\tau}}^{*}$ and $\mathrm{c}_{\tau}^{*}$, by

$$
c_{\tau}=c_{\tau},=\frac{1}{2}\left(c_{\tau}^{*}+c_{\tau}^{*},\right)
$$

is certainly feasible: the agent can achieve it by saving $m_{\tau}=p\left(e_{i \tau}-c_{\tau}\right\}>0$ when he is of age $\tau$, keeping this amount of money until he is of age $\tau$ ', and by spending it at that time. Given the specific form of the utility function and the fact that $\delta_{i}=1$, this new program yields a higher level of utility, since by strict concavity of $w_{i}$ :

$$
w_{i}\left(c_{\tau}\right)+w_{i}\left(c_{\tau},\right)>w_{i}\left(c_{\tau}^{*}\right)+w_{i}\left(c_{\tau}^{*},\right)
$$

Hence a contradiction, which proves the claim.

The result we just proved implies that if there is a type $i$ of agents which satisfies $(d)$ and $(\vec{e})$, then $\Gamma_{i} m_{i}(\bar{p})$ is positive for every solution $\bar{p}$ of $(A)$ when $\delta_{i}$ is equal to 1 . In that case, the system $(A)$ and $(B)$ has indeed a solution. It is intuitively clear that by continuity, $(A)$ and $(B)$ still has a solution if $\delta_{i}$ is close 
to unity. This heuristic argument justifies accordingly the following proposition (1).

(2)

Assume (a), (b) and (c) of the present Section. Assume moreover that there is a type $i$ of consumers which satisfies $(d)$ and $(e)$. Then the system $(A)$ and $(B)$ has a solution $i f \delta_{i}$ is close enough to 1.

Remark. Here again, it is understood that a stationary equilibrium is one where money has positive value. Under our assumptions on utility functions and endowments, it can be shown using standard methods of equilibrium theory that there exists a stationary equilibrium where money has zero value. In the case of a single good it corresponds to the autarkic state where every consumer consumes his own endowment in every period of his life.

(1) A rigorous proof of this proposition is given in Appendix B. 


\section{READINGS.}

1. ARCHIbald, G.C, and R.G. LiPSEY, Monetary and Value Theory : A Critique of Lange and Patinkin", Review of Economic Studies 26 (1958), 1-22.

2. Clawer, R. (ed.), Monetary Theory, Penguin Books, 1969.

3. FISHER, I., The Purchasing Power of Money, Kelley, New York, Revised Edition, 1963.

4. FRIEDMAN, M., "The Quantity Theory of Money : A Restatement", in Studies in the Quantity Theory of Money, Friedman (ed.), Chicago University Press, 1956.

5. GRANDMONT, J.M., "On the Short Run Equilibrium in a Monetary Economy", in Allocation Under Uncertainty, Equilibrium and Optimality, J. DREZE (ed.), MoMillan, 1974.

6. GRANDMONT, J.M. and G. LAROQUE, Money in the Pure Consumption Loan Model", Journal of Economic Theory 6 (1973), 382-395.

7 HICKS, J.R., Value and Capital, Oxford University Press, London, 2nd ed., 1946, chaps. IX, XX and Additional Note B.

8. HICKS, J.R., Critical Essays in Monetary Theory, Oxford University Press, London, 1967, chap. 4.

9. JOHNSON, H.G., Essays in Monetary Economics, George Allen and Unwin, London, 1967, chap. 1.

10. JoHNSON, H.G., Macroeconomics and Monetary Theory, Aldine Pub. Co., Chicago, 1972, chaps, 6, 7, 14 and 15.

11. LANGE, 0., "Say's Law : A Restatement and Criticism", in Studies in Mathematical Economics and Econometrics, Lange (ed.), Chicago University Press, 1942, pp. 49-68.

12. LANGE, 0., Price Flexibility and.Employment, Cowles Commission, 1944, chaps. I to $\mathrm{V}$.

13. MARSHALL, A., Money, Credit and Commerce, McMillan, 1924, chap. 4, pp. 38-50 as reprinted in CLOWER (Ed.). 
14. PATINKIN, Money Interest, and Prices, Harper and Row, New York, 2nd ed., 1965, chaps. II, III and VIII.

15. SAMUelson, P.A., "An Exact Consumption Loan Model of Interest With or Without the Social Contrivance of Money", Journal of Political Economy 66 (1958), 467-482.

16. SAMUELSON, P.A., "What Classical and Neoclassical Monetary Theory Really Was", Canadian Journal of Economics 1 (1968), 1-15. 